\title{
EXPLORING PREDICTING ROLE OF STUDENTS GRIT IN BOOSTING HOPE, MEANING IN LIFE AND SUBJECTIVE HAPPINESS AMONG UNDERGRADUATES OF UNIVERSITY
}

\author{
Hayat Muhammad*, Summiya Ahmad ${ }^{\dagger}$ \\ \& Muhammad Iltimas Khan
}

\begin{abstract}
The present research examines how the presence of students' psychological grit can boost up hope, meaning in life, and subjective happiness of 475 undergraduate students. To test this model, students' grit is used as predictor of presence of hope, meaning in life, and subjective happiness. Student's grit influences the passion and perseverance of the undergraduate students of the university to achieve their short and longterm goals. We administered grit scale, hope scale, meaning in life scale and subjective happiness scale to examine the predicted and criterion variables. Using correlation and regression (path analysis) analysis, findings of the study explored that students' psychological grit is the significant predictor of hope, meaning in life, and subjective happiness. This study was conducted only in one public university, where students come from diverse areas. Significance of the study is, it will help counselors, planners, policy makers etc. to enhance passion and perseverance of students predicting and increasing hope, meaning in life, and subjective happiness of the students in order to make them focused to achieve their goals and face the challenges of life.
\end{abstract}

Keywords: Students' Grit, Hope, Meaning, Happiness, Undergraduate Students

\footnotetext{
Department of Psychology, University of Peshawar.

Department of Psychology, University of Peshawar.

Department of Islamiyat, University of Peshawar.
} 


\section{Introduction}

Fully functioning individuals are those who are more directed towards their true self. A person with deepest and inner most desire, having the capability to be self-actualize can turn themselves into the best version of self. The main features of such individuals are that they are able to set their aims and goals, they can achieve them, shows more altruistic and helping behavior. These factors make them bring existence to their lives (Vainio \& Daukantaite, 2015). Positive growth is nothing without implicit motivation. Intrinsically, every person has the ability to grow and move to their best version of the self. This particular tendency of growth needs an environment, which helps to enhance potential; while certain environmental factors may develop hindrance to prevent him/her into reaching their appropriate goals (Rogers, 1961). Sub consciousness process are important in achieving selfactualization. It will help an individual to explore new experiences in life (Ryan, \& Deci, 2000; Emmons, 2003; Sheldon, Ryan, Deci, \& Kasser, 2004; Deci, \& Ryan, 2000).

As the modern world is now growing day by day, some individuals are still putting effort to achieve their goals (Beechler, \& Woodward, 2009; Greene, 2006). Those individuals, whose work is based on core motivation, are able to take some practical step to overcome the problem and obstacles they face in their lives (Ryan, Deci, \& Kessar, 2004; Deci, 1975).

Seligman (2002), positive psychology has its own impact in understanding the student's condition in reference to their mental health, career advancement, and academic success. Mental health professionals and researchers follow the frame work of positive psychology. Also, they have developed certain techniques and interventions to fulfill the goals related to those factors, which enhance the academic progress and all-encompassing mental health. Positive psychology devise, and targeting those strategies that will strengthen and enhance wellbeing, positive emotion and happiness (Seligman, 2002). Dispositional characteristics, which will push and drive individuals to get success while achieving life goals has recently been conceptualized as "grit" (Duckworth, Peterson, Mathews and Kelly, 2007).

\section{Grit}

Continue self- discipline, desire and determination are needed to chase and give attention to person related long term goals, and it is called grit (Duckworth, Peterson, Mathews, \& Kelly, 2007). A construct, grit is a composition of two factors i.e. perseverance of effort and consistency of interest (Duckworth \& Seligman, 2005). Some specific facets of conscientiousness like perseverance and industriousness are closely related to grit (Duckworth, Tsukayama, \& Kirby, 2013). 
The prophetic skill of grit is obvious in life and the mediational process of life. Kleiman, Adams, Kashdan, and Riskind (2013) reported that grit has indirect effect to reduce the suicidal ideation. So, it is concluded that grittier people have good psychological health. Moreover, grit has positive relation with academic achievement (Tang, Wang, Guo, \&Salmela-Aro, 2019); academic motivation too (Reraki, Celik, \&Saricam, 2015). Achieving academically is not only dependent upon the intelligence, but also desire and persistence (Duckworth, Peterson, Matthews, \& Kelly, 2007). In another study, Credé (2018) discussed that prophetic capability of grit is uncertain, so more studies needed to be done to explore the relationship.

The absence of the debilitating rudiments of the human experience is the simultaneous result of psychological well-being and the presence of meaning, enabling one's positive emotions, environmental mastery, health relationships, engagement, self-actualization. Psychological well-being is over, above and beyond the mere absence of psychological ill-being.It includes and considers a wider gamut of constructs other than what is customarily regarded as contentment (Seligman \& Csikszentmihalyi, 2000; Seligman, 2011).

In the previous era, positive psychology grew tremendously in different fields e.g., research, and mental health professional to increase attention about human strength (Duckworth, Steen, \& Seligman, 2005; Seligman \& Csikszentmihalyi, 2000). The attention has been diverted from mental illness to positive aspect of human being such as happiness, growth, hope, optimism, psychological well-being. Another important aspect of positive psychology is hope, which was discussed by Snyder et al. (1991). "Pathway thinking entail" is an ability to develop one or more workable paths to approach the goal. while agency thinking is the ability of using pathways in order to reach the goals desired (Snyder, 2002). The above mentioned elements are interrelated so without any one of them, the concept of hope is incomplete (Magaletta \& Oliver, 1999; Snyder, 2002). Hope is a cognitive element and accompanied with emotions (Snyder, Cheavens, \& Michael, 1999; Snyder et al., 1991).

\section{Hope}

Hope is the main motivating force in life. Hope is the only indication that life exists. In previous decades, hope is considered to be similar to dreams, wishes etc. Snyder, who actually coined the term hope and explained as a positive motivation of successful agency and pathways that are organized in an interactive manner, and consist of pathways thinking that operate through various means for achieving the goals desired. Snyder et al (1991) further proposed a theory, which is called hope theory, and is divided into two components: Pathways thinking and agency thinking. Feldman \& Dreher (2012) explain that people's belief and plan to get most wanted 
objective is called pathway's thinking, while people have idea about self, such as they have ability to start goal oriented action and choose the different ways to achieve the goal, called agency thinking (Snyder, Michael \& Cheavens, 1999).

Close relationship between hope and students' academic performance (Snyder et al., 2002), achievement in goal (Feldman, Rand, \& KahleWrobleski, 2009) academic success in future and sound mental health was explored by researchers (Marques, Pais-Ribeiro, \& Lopez, 2011), and meaning in life (Vela, Lerma, et al., 2014). After investigating the relationship between mental health and academic success; in particular adolescents, it was further examined that hope has the close relationship with student's academic performance (Marques et al., 2011). Attainment of future goals, determination and persistent interest towards long-term goals might increase if college students have hope (Vela et al., 2014; Feldman \& Dreher, 2012).

\section{Meaning in Life}

According to Steger, Frazier, Oishi, \& Kaler (2006), one of the psychological strengths is meaning in life and basic contributor in the field of positive psychology (Seligman, Ernst, Gillham, Reivich, \&Linkins, 2009). Meaning in life plays a role of indicator in the prediction of subjective well-being (Steger \& Kashdan, 2007). Individuals having meaning in life do not make it similar to a happy life or a life free of depression, sadness or despair. Meaning in life is not a new domain for argumentation and discussion (Kernes \& Kunnier, 2008). There are two components of meaning in life, which are search for meaning in life and presence of meaning in life as proposed by Steger and Shin (2010). Research indicated that positive and negative mental health outcomes are the consequence of lack of meaning in life (Moomal, 1999; Steger, Frezier, Oishi, \& Kaler, 2006; Zika \& Chamberlain, 1992). There is an increase in psychological literature, which indicates an association between mental health, academic performance and meaning in life (Brassai, Piko, \& Steger, 2011; Steger and Shin, 2010; Vela, Castro et al., 2014). Most of the researchers explored the relationship between meaning in life and happiness, it is also imperatively important to investigate the relationship between meaning in life and students' psychological grit.

Adolescence is defined as developmental period, where individuals start to pursue purpose in their life in accordance with their beliefs (Damon, Menon, Cotton \& Bronk, 2003). Some individuals don't go beyond their set beliefs. Consequently, during the adolescence, if they don't develop such belief, they will be unable to motivating belief in their later life. As a consequence, this double mindedness may lead to personal decline and social incompetence (Damon et al., 2003). Previous studies explored grit 
relationship with high level of meaning in life (Hill et al., 2016; Kleiman et al., 2013). Those individual whose perception of meaning in life is high are more inclined to pursue their lives goals, which is considered the main feature of grit (Feldman \& Snyder, 2005).

In addition, previous study showed that grit is related to meaning in life (Hill et al., 2016; Kleiman et al., 2013). A key element of grit meaning in life is in reference to achieving the goal (Feldman \& Snyder, 2005). In fact, to recognize one's purpose in life is helpful to have an ability to find developmental task (Bronk, 2014). Brassai et al. explored that the adolescents having higher meaning in life showed lesser health behavioral problem, drug abuse, and lack of exercise, and shows more altruistic problems(De Goede, et at., 1999). Higher will be the hope lower will be the suicidal ideation (Brassai, 2011; Dogra, et at., 2011; Kleiman, et al., 2013; $\mathrm{Wu}$, et al., 2013).Thus having purpose in life is proactive factor for mental health problems among Chinese people and this proactive factor will help in acculturation among Chinese students in Australia (Pan, et at., 2008; Pan, et al., 2010; Shek, et al., 1993).

\section{Happiness}

Subjective happiness is another factor leading to student's achievement. It is defined by Diener, Suh Lucas, and Smith (1999) explains it as a phenomenon, which includes emotional responses of people, judgements of life satisfaction globally and domain satisfaction. (p. 277). Once a person's basic needs have been met, his/her focus may shift to understand issues of happiness and life satisfaction. Lyubomirsky and Tucker (1998) reported that happiness and positivity towards life is in direct proportion. Similarly, subjective happiness is leading factor towards academic achievement.

Happiness is a psychological state of pleasure, well-being and satisfaction (Otake, Shimai, Tanaka-Matumi, Otsui, \& Fredrickson, 2006; Lyubmomirsky, 2001). Happiness is the most renowned concept in positive psychology and originate to be a noteworthy part of life and human experience (Lyubomirsky, 2001).Another finding suggested that well-being and happiness are predictor of good mental health (Chaplin, 2006; Liem, \& Dillon, 2010; Valois, Paxton, Zullig \& Huebbner, 2006).

Happiness is associated with academic achievements and work on it was done by Duckworth and Quinn (2007). Chen and Lu (2009) describe grades, school satisfaction, and subjective happiness and academic success in Taiwanese students. There is a close association among happiness, spirituality and meaningful life (Vela \& Castro, 2014). There is an increase in psychological literature, which indicates an association between mental health, academic performance and meaning in life (Brassai, Piko, \& Steger, 2011; Steger and Shin, 2010; Vela, Castro et al., 2014). Most of the researchers explored the relationship between meaning in life and happiness, 
it is also imperatively important to investigate the relationship between meaning in life and students' psychological grit.

\section{Rationale of the Study}

Student's grit is playing very important role in student's academic achievement and passion in their life's goals attainment. Boosting student's academic performance and concentration on their goal's achievement requires high level of hope, clarity in meaning in life and subjective happiness. Studies conducted in other cultural context shows significant relationship between grit and hope; grit and meaning in life, grit and subjective happiness. Literature related to these variables is not available in our cultural context, and requires comprehensive and serious consideration. The current study is carried out with the intention to find out the predicting role of grit in relation to hope, meaning in life and happiness. The study findings will help academician, policy maker generally and students specifically to increase grit (perseverance and passion) which will boost hope, meaning and happiness. These factors are the prerequisite for academic achievements, attainment of life goals and successful life.

This study is comprised of the following objectives and hypotheses:

\section{Objectives}

1. To explore the predicting role of student's grit in boosting hope, meaning in life and subjective happiness.

2. To examine the relationship among grit, hope, meaning in life and subjective happiness.

3. To find the difference among hope, meaning in life, subjective happiness and grit on gender basis.

\section{Hypotheses}

H1: Students grit will predict high level of hope, meaning in life and subjective happiness.

$\mathrm{H} 2$ : There will be significant correlation among grit, hope, meaning in life and subjective happiness.

H3: There will be no significant difference between male and female in relation to grit, hope, meaning in life and subjective happiness. 


\section{Method}

\section{Conceptual Model of the Study}

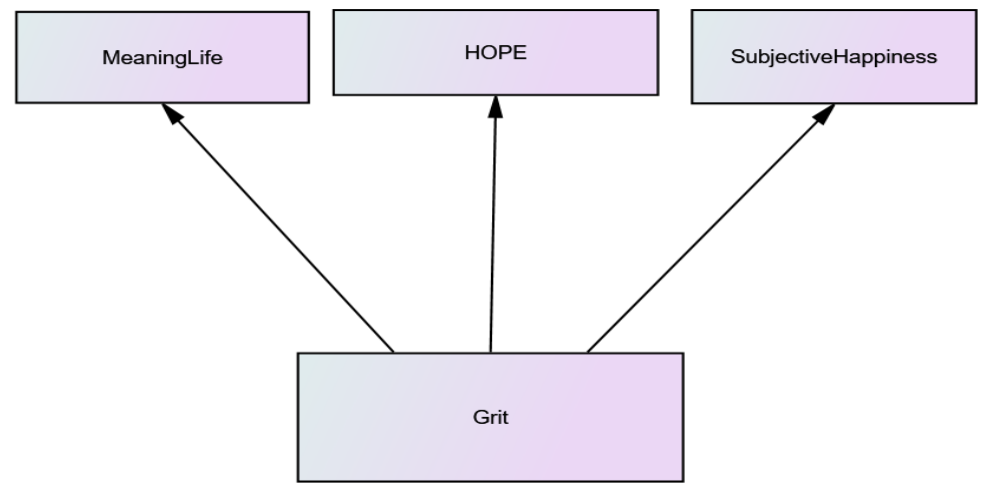

\section{Participants}

Population of this study was undergraduate students from University of Peshawar (UOP). Purposive sampling technique was used to collect data for the current study. Sample size for this study was 475 undergraduate students, which was further divided into male (47.57\%) and female $(52.42 \%)$. Participants average age was 21.25 years $(S D=3.42)$. Only students enrolled in undergraduate scheme of study were included for data analysis. Data collection was spread to all the running semesters of undergraduate program of fall semester $\left(2^{\text {nd }}\right.$ semester, $4^{\text {th }}$ semester, $6^{\text {th }}$ semester and $8^{\text {th }}$ semester.

\section{INSTRUMENTS}

Psychological Grit Scale. Grit short scale is developed by Duckworth and Quinn (2009). It is used to measure perseverance and passion for longterm goals. The protocol consists of eight statements, which are based on a 5-point Likert scale which ranges from very much like me (5) to not at all like me (1). Higher the scores on the scale will show psychological grit with higher perception Duckworth et al. (2007) investigated predictive validity of psychological grit among undergraduates, who changed their career in life time many times. Reliability coefficients of the protocol ranges from .78 to .82 (Duckworth et al., 2011). In the current study, evidence of reliability of grit scale with undergraduate students of university was acceptable at .81 .

Hope Scale. The Hope Scale developed by Snyder et al. (1991) with the intention to measure respondents' attitudes toward objectives and goals. Hope scale is further subdivided into two subscales: Agency and Pathways. Hope scale is comprised of eight statements, which is evaluated on Likert scale of 8-points which ranges from definitely true (8) to definitely false (1). Discriminant and concurrent validity between hope, state positive and 
negative affect and self-esteem was explored by Snyder et al. (1996).Hope scale reliability coefficients ranges from 0.77 to 0.81 (Visser, Loess, Ieglic, \& Hirsch, 2012; Sun, Tan, Fan, \&Tsui, 2014). For current study, the Cronbach's alpha was 0.84 .

Meaning in Life Questionnaire (MLQ). This assessment tool is developed by Steger et al. (2006), which measures search and presence of meaning in life in students or adults. This is self-reported inventory. MLQ is comprised of 10 statements based on Likert scale of 7-points, which ranges from Absolutely True (7) to Absolutely Untrue (1). The reliability coefficients of MLQ ranges from 0.70 to 0.93 on the Presence of Meaning in Life subscale and 0.87 to 0.90 on the Search for Meaning in Life subscale (Park et al., 2010; Sunn\& O'Brien, 2009; Vela, Lerma, et al., 2014). Cronbach alpha reliability for current study was 0.90 .

Subjective Happiness scale (SHS). Lyubomirsky and Lepper (1999) developed this scale which is 4 -items Likert-type scale. The protocol with the help of statements measures global subjective happiness. The participants in it rate themselves or else do their comparison with others. Lyubomirsky and Lepper (1999), in validation study found adequate reliability index, with alpha coefficients varying from 0.80 to 0.94 in 14 different samples $(\mathrm{N}=2.732)$.

\section{Operational Definition}

Grit: The score on the psychological grit scale (Duckworth and Quinn, 2009) will measure the grit of the students.

Hope: The hope scale (Snyder et al., 1991) will measure the student's hope. Meaning in Life: Student's meaning in life will be measured by Meaning in Life Questionnaire (Steger et al., 2006).

Subjective Happiness: The score on the subjective happiness scale will measure the student's happiness (Lyubomirsky \& Lepper (1999).

\section{Procedure}

Several steps were implemented for collection of data. Permission was obtained from Institutional Heads in the very first step. In second step, students were approached by using the strategy of purposive sampling technique. In the third step, students were briefed about their participation, which is voluntary participation and no credit will come in reward after participating in the data collection. Questionnaires were distributed during class time and completion took almost 15 to 20 minutes. In final step, after completion of data collection, it was analyzed and interpreted. 


\section{Data Analysis}

Statistical Power Analysis. To establish power for the intended research design at the level of 0.81 based on $\alpha=.05$ by conducting an a priori power analysis by using G*Power Program (Faul, Erdfelder, Lang, \& Buchner, 2007). To identify a medium effect between predictor variable to estimate change among scores on hope, meaning in life and subjective happiness. It is regarded that our research results dependable for identifying relationship between predictor and criterion variables on a given sample of 475 participants.

Preliminary Analysis. Bivariate correlations were assessed among the variables. Association among criterion and predictor variables were given low with the inclusion of all predictor variables in a model was prudent.

Primary Analysis. Relationship between predictor and criterion variables was modeled by applying multiple regression model to evaluate our hypothesis related to the degree that psychological grit predicted hope, meaning in life and subjective happiness. In this model, 1 predicted variable was regressed onto scores of hope, meaning in life and subjective happiness and also evaluated regression coefficients estimating applied and practical significance.

Table 1: Evaluation table of bivariate correlation among criterion and predictive variables

\begin{tabular}{lcccc}
\hline Variable & $\mathbf{1}$ & $\mathbf{2}$ & $\mathbf{3}$ & $\mathbf{4}$ \\
\hline Grit & -- & $.320^{* *}$ & $.278^{* *}$ & $.103^{*}$ \\
Hope & & - & $.448^{* *}$ & $.176^{* *}$ \\
Meaning in Life & & & - & $.220^{* *}$ \\
Subjective Happiness & & & & - \\
\hline$p<.001$ & & & &
\end{tabular}

\section{Results}

Regression analysis was conducted to investigate the variable predicting hope, meaning in life and subjective happiness (see Tables No. 2, 3, 4). Statistically significant model is yielded by regression analysis, $F(4,471)=$ $53.26,39.66$ and 5.05, $\mathrm{p}<.001, \mathrm{R}_{2}=.32, .27$ and .10 , which indicates a large effect size in which $32 \%, 27 \%$ and $10 \%$ of the change is accounted by predictor among the scores estimating hope, meaning in life and subjective happiness. Scores, which were associated with the participants psychological grit within the model measured a very significant predictive relationship ( $B$ $=.38, .26$ and $.05 p<.0001, \mathrm{sr}_{2}=.32, .27$ and .10$)$, which is the indication of medium effect size. Result findings suggest that $32 \%, 27 \%$ and $10 \%$ of change in participants' scores on hope, meaning in life and subjective 
happiness are attributed to the student's psychological grit indicative of a medium effect size.

Table 2:Summary table of Grit predicting Hope

\begin{tabular}{lccccccc}
\hline Variables & $\mathbf{B}$ & $\mathbf{S E B}$ & $\boldsymbol{\beta}$ & $\mathbf{t}$ & $\mathbf{S i g}$ & $\mathbf{F}$ & $\mathbf{R}^{\mathbf{2}}$ \\
\hline $\begin{array}{l}\text { Hope } \\
\text { Grit }\end{array}$ & & & & & & 53.268 & .320 \\
\hline
\end{tabular}

Table 3: Summary table of Grit predicting Meaning in Life

\begin{tabular}{lccccccc}
\hline Variables & B & SEB & $\boldsymbol{\beta}$ & $\mathbf{t}$ & Sig & $\mathbf{F}$ & $\mathbf{R}^{\mathbf{2}}$ \\
\hline $\begin{array}{l}\text { Meaning in Life } \\
\text { Grit }\end{array}$ & & & & & & 39.664 & .278 \\
\hline
\end{tabular}

Table 4: Summary table of Grit predicting Subjective Happiness

\begin{tabular}{lccccccc}
\hline Variables & B & SEB & $\boldsymbol{\beta}$ & $\mathbf{t}$ & Sig & $\mathbf{F}$ & $\mathbf{R}^{2}$ \\
\hline $\begin{array}{l}\text { Subjective Happiness } \\
\text { Grit }\end{array}$ & & & & & & 5.054 & .103 \\
\hline
\end{tabular}

Path Model of Regression (Predictor and Criterion Variables)

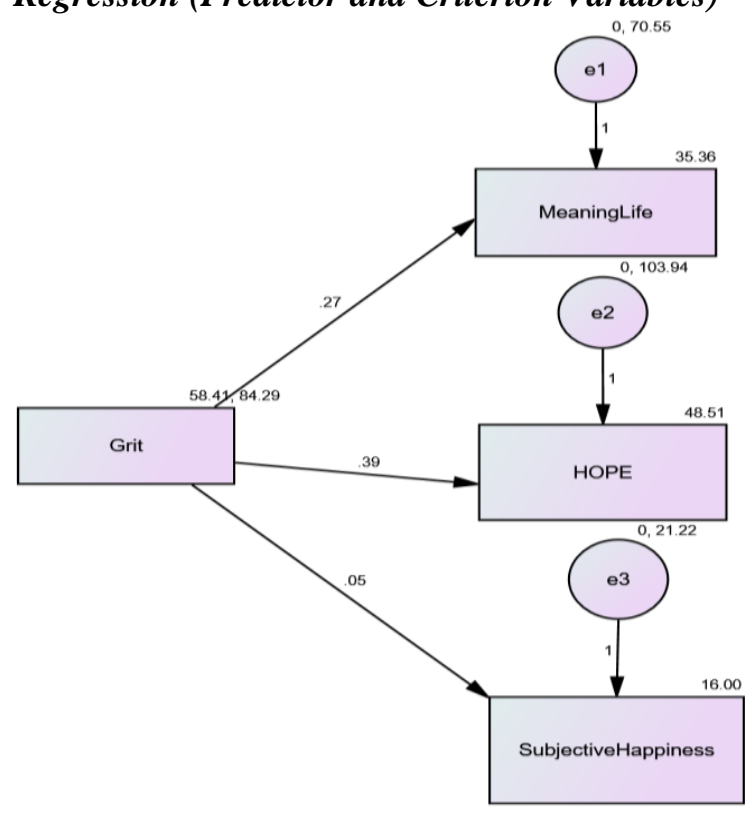


Comparative analysis was done to find out the difference among male and female students through independent sample t test (see table 5). As it was hypothesized that there will be no differences between male and female students in reference to predicting and criterion variables. Result yielded that there is difference between male and female students on scores of hope $(\mathrm{M}=$ $69.33 \& \mathrm{M}=72.58, p=.001$ respectively).

Table 5: Means, standard deviations and t-value of the Male and Female students $(\mathrm{N}=475)$

\begin{tabular}{lccccccccc}
\hline Variables & \multicolumn{2}{c}{$\begin{array}{c}\text { Male } \\
(\mathbf{n = 2 2 6})\end{array}$} & \multicolumn{2}{c}{$\begin{array}{c}\text { Female } \\
(\mathbf{n = 2 4 9})\end{array}$} & & & \multicolumn{2}{c}{ 95\% CI } & Cohen's d \\
& $\mathbf{M}$ & S.D & $\mathbf{M}$ & S.D & $\mathbf{t}$ & $\mathbf{p}$ & $\mathbf{L L}$ & $\mathbf{U L}$ & \\
Grit & 57.67 & 9.20 & 59.02 & 9.16 & -1.586 & .113 & -3.006 & .320 & 0.025 \\
Hope & 69.33 & 9.94 & 72.58 & 11.26 & -3.295 & .001 & -5.196 & -1.313 & 0.039 \\
Meaning in & 50.48 & 9.159 & 51.24 & 8.39 & -.936 & .350 & -2.341 & .830 & 0.284 \\
Life & & & & & & & & & \\
Subjective & 19.12 & 4.43 & 18.97 & 4.83 & .340 & .734 & -.696 & .986 & 0.072 \\
Happiness & & & & & & & & & \\
\hline
\end{tabular}

$p<.001$

\section{Discussion}

This study findings contribute in extending our understanding the association between student's grit, hope, meaning in life and subjective happiness among undergraduate students at a university level in a multidimensional manner. Results of the current study have the strength to devise strategies for intervention to improve the psychological grit among students, which have a direct impact on the improvement of hope, meaning in life and subjective happiness. In the findings of this study, it is extracted that students psychological grit have strong impact and is predictor of hope, meaning in life and subjective happiness. In the light of our findings, it can be suggested that as we increase the students' psychological grit, will also increase the level of student's hope, meaning in life and subjective happiness.

Students' engagement occurs when students are psychologically engaged in learning, which is linked with psychological wellbeing (Lamborn, Newmann \& Wehlage, 1992). Students can be engaged despite facing challenges and obstacles, students will involve in their work, remain persistent and even feel pride of accomplishing their assigned tasks (Bomia et .al, 1997). Psychological wellbeing will increase the stamina of students. According to Duckworht (2013), grit is the disposition based on passion and perseverance, which are required to pursue long term goals, which are sustained over time and emphasize to increase the stamina.

It was hypothesized that students' psychological grit will predict students hope, meaning in life and subjective happiness. Until now, number 
of studies explored the positive psychology factors predicted students' psychological grit. In this study, girt was taken as a criterion variable for the prediction of presence of hope, meaning and happiness among students of undergraduate program at a university level. Study result revealed that student's psychological grit is significant predictor of students' hope, meaning and happiness. Maddi et al. (2013) identified that the concept of "existential courage", which is the ability to respond and remain flexible and courageous to the challenges one faces in life, which is something to be missing in the current definition of grit. The result of research conduct by Tiittanen M. (2014) suggested that grit is comprised of such courage that is required to bring harmony in life. It is suggested that gritty people can face life's challenges flexibly, rather than remaining hard and rigid, which will strengthen and ensure the maintenance of wellbeing. There is positive correlation between grit, hope, meaning in life and happiness. Increase in psychological grit of students will increase students' hope, meaning and happiness. These findings are consistent with the findings of study conducted by Skinner, Pitzer, and Brule (2014), which mentioned that engagement in work and motivational resilience are positively correlated.

The outcome of the study was similar with previous study who had been conducted in western cultural context (Magaletta \& Oliver, 1999; Snyder, 2002; Snyder et al., 1991). Another study conducted by Snyder (2002) revealed that those individuals who have high level of hope showed high level of self-efficacy, academic achievement, and problem-solving ability. The academic self-efficacy is linked to the cognitive process of hope which is called agency pathways, leads to future goal and firm behavior (Magaletta \& Oliver, 1999). Another study revealed that high hoped individual is flexible and find outs different paths to achieve goal; although face uncertainty in attainability of goal. Vice versa, low hope individuals are rigid, poor decision making ability, and unable to find proper rout to goals (Snyder,2002) and poor problem-solving ability (Cannon et al. 1999). Mutual relationship between self-efficacy, problem solving ability and hope is found e.g., higher the selfefficacy higher will be problem solving ability and hope.

Grit has strong relationship with meaning in life (Hill et al., 2016; Kleiman et al., 2013). One of main qualities of gritty person is that they are hard working to achieve long term goal despite they face hurdles to achieve it. Further they have higher level of commitment towards stubborn goal (George \& Park, 2016). High meaning in life associated with lower level of depression. It helps to reduce cognitive distortion. Likewise, Steger et al. (2006) reported meaning in life leads low depression.

Vela, J. C et al. (2017), hope is the strongest variable in forecasting the presence of grit among college students. Feldman and Dreher, (2012) reported that following and achieving goal is just to have hope in life. Further Snyder et al., (1999) explained that hope increase the confidence to achieve the goal. 
Psychological well-being, subjective happiness, meaning in life are main factors to understand the phenomena of grit; while such above mentioned concepts are not playing any part in developing grit. Vela, Smith, et al., (2017) reported that hope and grit are positively associated with each other. The current study shows vice versa result in which, grit predicted and having significant correlation with hope, meaning in life and happiness among undergrade students.

Another study conducted in the past which explored that those individuals who have higher meaning in life shows high level of grit (Hill et al., 2016; Kleiman et al., 2013). Purpose in life is an important factor associated with pursuing goal, and this in turn leads to meaning in life (George \& Park, 2016). Life satisfaction leads towards grit conduct on general population (Singh \& Jha. 2008; Vainio \& Daukantaite, 2015).

The relationship between grit and happiness were found in fresh college students. Similarly, another study indicated that gritter students were happy in their life (Hill, Burrow, and Bronk, 2016, Singh and Jha,2008, Akbağ and Ümmet, 2017).

The relation relationship grit, hope, meaning in life and happiness, no significant differences between genders were found (Feldman \& Snyder, 2005; Snyder et al., 1991; Snyder et al., 1996). Result of the current study regarding gender difference is inconsistent with a meta-analysis conducted by Yarcheski and Mahon (2014), who found that 7 out 13 studies concluded gender differences were present in hope. Esteves et al. (2013) that found there is no relation of hope and age, but this study focused on counseling process and role of teacher in educational setting related to hope. The sequential strategy is that if student comes with low hope a group/ individual intervention may imply to develop goal, motivation and to teach them how to achieve the goal (Shorey, Snyder, Yang, \& Lewin, 2003).

\section{Limitations}

There are certain limitations in the current studies. Self-perception of the student related to positive psychology may impair the comprehension related to the variables like grit, hope, happiness, meaning in life. Sample was collected from the same area and due to similar characteristics, it affects the generalizability of the outcomes. Findings are applicable to the students of undergraduate program.

\section{Conclusion and Research Implications}

The basic purpose of the study was to explore the role of psychological grit as factor in the development of hope, meaning in life and happiness in undergraduate students. On the basis of present study, it has been concluded that student's grit is strongly foretold hope, meaning and happiness. Student's 
is incremental factor towards achievement of the goal. Further description is related to developing and designing intervention program (psychological in nature), which is beneficial to the student to increase the student's grit. Moreover, the current study showed significant relationship among hope, subjective happiness, and meaning in life with high grit in students.

\section{References}

Abolghasemi, A., \& Varaniyab, S. T. (2010). Resilience and perceived stress: predictors of life satisfaction in the students of success and failure. Procedia-Social and Behavioral Sciences, 5, 748-752.

Akbağ, M., \& Ümmet, D. (2017). Predictive role of grit and basic psychological needs satisfaction on subjective well-being for young adults. Journal of Education and Practice, 8(26), 127-135.

Almeida, D.J. (2016). Understanding grit in the context of higher education. In M. B. Paulsen (Ed.), Higher education: Handbook of theory and research (31 ed., pp. 559-609). Switzerland: Springer International Publishing.

Arnett, J.J. (2000). Emerging adulthood-A theory of development from the late teens through the twenties. Am. Psychol, 55, 469-480.

Barresi, J. (1999). On becoming a person. Philosophical Psychology, 12(1), 79-98.

Bomia, L., Beluzo, L., Demeester, D., Elander, K., Johnson, M., \& Sheldon, B. (1997). The impact of teaching strategies on intrinsic motivation. Champaign, IL: ERIC Clearinghouse on Elementary and Early Childhood Education.

Brassai, L., Piko, B.F., \& Steger, M.F. (2011). Meaning in life: Is it a protective factor for adolescents' psychological health? International Journal of Behavioral Medicine, 18, 44-51. doi:10.1007/s12529-0109089-6.

Bronk, K.C. (2011). The role of purpose in life in healthy identity formation: A grounded model. New Dir. Youth Dev, 132, 31-44.

Bronk, K.C. (2014). Purpose in Life: A Critical Component of Optimal Youth Development; Springer Netherlands: Heidelberg, Germany.

Carver, C.S. (1998). Resilience and thriving: Issues, models, and linkages. Journal of social issues, 54(2), 245-266.

Chaplin, T.M. (2006). Anger, happiness, and sadness: associations with depressive symptoms in late adolescence. Journal of Youth and Adolescence, 35(6), $977-986$.

Credé, M. (2018). What shall we do about grit? A critical review of what we know and what we don't know. Educational Researcher, 47(9), 606611.https://doi.org/10.3102/0013189X18801322 
De Goede, M., Spruijt, E., Iedema, J., \&Meeus, W. (1999). How do vocational and relationship stressors and identity formation affect adolescent mental health? J. Adolesc. Health, 25, 14-20.

Deci, E.L., \& Ryan, R.M. (1975). Intrinsic motivation. John Wiley \& Sons, Inc.

Deci, E.L., \& Ryan, R.M. (2000). The" what" and" why" of goal pursuits: Human needs and the self-determination of behavior. Psychological inquiry, 11(4), 227-268.

Diener, E., Larsen, R.J., \& Emmons, R.A. (1984). Person× Situation interactions: Choice of situations and congruence response models. Journal of personality and social psychology, 47(3), 580.

Dogra, A.K., Basu, S., \& Das, S. (2011).Impact of meaning in life and reasons for living to hope and suicidal ideation: A study among college students. SIS J. Proj. Psychol. Ment. Health, 18, 89.

Duckworth, A.L., Peterson, C., Matthews, M.D., \& Kelly, D.R. (2007). Grit: Perseverance and passion for long-term goals Journal of Personality and Social Psychology 92(6):1087-101 https://doi org/10 1037/002235149261087

Duckworth, A.L., \& Seligman, M.E.P. (2005). Self-discipline outdoes IQ in predicting academic performance of adolescents Psychological Science, 16(12), 939-944 https:// doi org/10 1111/j 1467-9280 200501641

Duckworth, A.L., \& Seligman, M.E.P. (2006). Self-discipline gives girls the edge: Gender in self-discipline, grades, and achievement test scores Journal of Educational Psychology, 98(1), 198-208

Duckworth, A.L., Tsukayama, E., \& Kirby, T.A. (2013). Is it really selfcontrol? Examining the predictive power of the delay of gratification task Personality \& Social Psychology Bulletin, 39(7), 843-55 https://doi org/10 1177/0146167213482589

Duckworth, A.L., \&Eskreis-Winkler, L. (2013). True grit. The observer, 26(4), 1-3.

Duckworth, A.L., and Quinn, P.D. (2009). Development and validation of the short grit scale (Grit-S). Journal of Personality Assessment. 91, 166-174. doi: 10.1080/ 00223890802634290

Duckworth, A.L., Kirby, T.A., Tsukayama, E., Berstein, H., \& Ericsson, K. A. (2011). Deliberate practice spells success why grittier competitors triumph at the national spelling bee. Social psychological and personality science, 2(2), 174-181.

Duckworth, A.L., Peterson, C., Matthews, M.D., \& Kelly, D.R. (2007). Grit: Perseverance and passion for long-term goals. Journal of Personality and Social Psychology, 92(6), 1087-1101. https://doi.org/10.1037/0022-3514.92.6.1087

Duckworth, A., \& Gross, J.J. (2014). Self-control and grit: Related but separable determinants of success. Current Directions in Psychological Science, 23(5), 319-325. 
Duckworth, A.L., Kirby, T.A., Tsukayama, E., Berstein, H., \& Ericsson, K. A. (2011). Deliberate practice spells success why grittier competitors triumph at the national spelling bee. Social Psychological and Personality Science, 2(2), 174-181.

Eskreis-Winkler, Duckworth, A.L., Shulman, E.P., \& Beal, S. (2014). The grit effect: Predicting retention in the military, the workplace, school and marriage. Frontiers in Psychology, 5, 1-29. doi:10.3389/fpsyg.2014.00036.

Feldman, D.B., \& Dreher, D.E. (2012). Can hope be changed in 90 minutes? Testing the efficacy of a single-session goal-pursuit intervention for college students? Journal of Happiness Studies, 13, 745-759. doi:10.1007/s10902-011-9292-4.

Feldman, D.B., \& Snyder, C.R. (2005). Hope and the meaningful life: Theoretical and empirical associations between goal-directed thinking and life meaning. Journal of Social \& Clinical Psychology, 24, 401-421.

Feldman, D.B., Rand, K.L., \& Kahle-Wrobleski, K. (2009). Hope and goal attainment: Testing a basic prediction of hope theory. Journal of Social and Clinical Psychology, 28, 479-497.

George, L.S., \& Park, C.L. (2016). Meaning in life as comprehension, purpose, and mattering: Toward integration and new research questions. Review of General Psychology, 20, 205-220.

Hartley, M.T. (2016). Investigating the relationship of resilience to academic persistence in college students with mental health issues. Rehabilitation Counseling Bulletin, 56, 240-250.

Hill, P.L., Burrow, A.L., \& Bronk, K.C. (2016). Persevering with positivity and purpose: An examination of purpose commitment and positive affect as predictors of grit. Journal of Happiness Studies, 17(1), 257269. https://doi.org/10.1007/s10902-014-9593-5

Kernes, J.L. \& Kinder, R.T. (2008). Meaning in psychologists' personal and professional lives. Journal of Humanistic Psychology, 48 (2), 196 - 220.

Kleiman, E.M., Adams, L.M., Kashdan, T.B., \& Riskind, J.H. (2013). Gratitude and grit indirectly reduce risk of suicidal ideations by enhancing meaning in life: Evidence for a mediated moderation model. Journal of Research in Personality, 47, 539-546. https://doi.org/10.1016/j.jrp.2013.04.007

Liem, J.H., Lustig, K. \& Dillon, C. (2010). Depressive symptoms and life satisfaction among emerging adults: a comparison of high school dropouts and graduates. Journal of Adult Development, 17,33-43.

Lyubormirsky, S. (2001). Why are some people happier than other? the role of cognitive and motivational processes in well-being. American Psychologist, 56(3), 239 - 249.

Maddi, S.R., Erwin, L.M., Carmody, C.L., Villarreal, B.J., White, M., \& Gundersen, K.K. (2013). Relationship of hardiness, grit, and emotional 
intelligence to internet addiction, excessive consumer spending, and gambling. The Journal of Positive Psychology, 8(2), 128-134.

Maddi, S.R., Matthews, M.D., Kelly, D.R., Villarreal, B., \& White, M. (2012). The role of hardiness and grit in predicting performance and retention of USMA cadets. Military Psychology, 24, 19-28.

Marques, S.C., Pais-Ribeiro, J.L., \& Lopez, S.J. (2011). The role of positive psychology constructs in predicting mental health and academic achievement in children and adolescents: A two-year longitudinal study. Journal of Happiness Studies, 12, 1049-1062. doi:10.1007/s109020109244-4.

Mason, H.D. (2018). Grit and academic performance among first year university students: A brief report. Journal of Psychology in Africa, 28(1), 66-68.

McCabe, K. \& Barnett, D. (2000). First comes work, then comes marriage: future orientation among African american young adolescents. Family Relations, 49, 63-70.

McCuUough, G., Huebner, E.S. \& Laughlin, J.E. (2000). Life events, selfconcept, and adolescents' positive subjective well-being. Psychology in the Schools, 37(3) $281-290$.

Moomal, Z. (1999). The relationship between meaning in life and mental well-being. South African Journal of Psychology, 29(1), 42 - 49.

Newman, F.M., Wehlage, G.G. \& Lamborn, S.D. (1992) The Significance and Sources of Student Engagement. In: Newman, F.M., Ed., Student Engagement and Achievement in American Secondary Schools, Teachers College Press, New York, 11-39.

Otake, K., Shimai, S., Tanaka-Matsumi, J., Otsui, K. \& Fredrickson, B. (2006). Happy people become happier through kindness: a counting kindnesses intervention. Journal of Happiness Studies, 7,361- 375.

Oyserman, D., Bybee, D. \& Terry, K. (2006). Possible selves and academic outcomes: how and when possible selves impel action. Journal of Personality and Social Psychology, 91 (1), 188 - 204.

Pan, J.Y., Wong, D.F.K., Joubert, L., \& Chan, C.L.W. (2010). The protective function of meaning of life on life satisfaction among Chinese students in Australia and Hong Kong: A cross-cultural comparative study. J. Am. Coll. Health, 57, 221-231.

Pan, J.Y., Wong, D.F.K., Chan, C.L.W., \& Joubert, L. (2008).Meaning of life as a protective factor of positive affect in acculturation: A resilience framework and a cross-cultural comparison. Int. J. Intercult. Relat, 32, 505-514.

Reed, J., Pritschet, B.L., \& Cutton, D.M. (2013). Grit, conscientiousness, and the transtheoretical model of change for exercise behaviour. Journal of Health Psychology, 18(5), 612-619.

Reraki, M., Celik, I., \& Saricam, H. (2015). Grit as a mediator of the relationship between motivation and academic achievement. Ozean 
and Subjective Happiness among Undergraduates of University

Journal of Social Science, $\quad 8(1), \quad 19-32$. https://doi.org/10.13140/RG.2.2.15063.78240

Robertson-Kraft, C., \& Duckworth, A.L. (2014). True grit: Trait-level perseverance and passion for long-term goals predicts effectiveness and retention among novice teachers. Teachers College Record, 116, 1-25.

Rogers, C.R. (1957). On becoming a person. S. Doniger.

Ryan, R.M., \& Deci, E.L. (2000). Self-determination theory and the facilitation of intrinsic motivation, social development, and well-being. American psychologist, 55(1), 68.

Ryff, C.D. (1989). Happiness is everything, or is it? Explorations on the meaning of psychological well-being. Journal of Personality and Social Psychology, 57(6), 1069.

Ryff, C.D. (2017). Eudaimonic well-being, inequality, and health: Recent findings and future directions. International Review of Economy, 64, $159-178$.

Ryff, C.D. (2013). Eudaimonic well-being and health: Mapping consequences of self-realization In A. S. Waterman (Ed.). The best within us: Positive psychology perspectives on eudaimonia,77-98. Washington, DC US: American Psychological Association.

Salles, A., Cohen, G.L., \& Mueller, C.M. (2014). The relationship between grit and resident well-being. The American Journal of Surgery, 207(2), 251-254.

Seligman, M. (2011). Flourish: A new understanding of happiness, wellbeing-and how to achieve them. Nicholas Brealey Pub.

Seligman, M.E. (2002). Authentic happiness: Using the new positive psychology to realize your potential for lasting fulfillment. New York, NY: Free Press.

Seligman, M.E. (2011). Flourish. New York: Simon \& Schuster.

Seligman, M.E.P. and Csikszentmihalyi, M., 2000. Positive Psychology: An Introduction. American Psychologist, 55, 5-14.

Seligman, M.E., Ernst, R.M., Gillham, J., Reivich, K., \& Linkins, M. (2009). Positive education: Positive psychology and classroom interventions. Oxford Review of Education, 35, 293-311.

Seligman, M.E., Ernst, R.M., Gillham, J., Reivich, K., \& Linkins, M. (2009). Positive education: Positive psychology and classroom interventions. Oxford Review of Education, 35, 293-311.

Shek, D.T. (1993). The Chinese Purpose-in-Life Test and psychological well-being in Chinese college students. Int. Forum Logother, 16, 35-42.

Sheldon, K.M., Abad, N., Ferguson, Y., Gunz, A., Houser-Marko, L., Nichols, C.P., \& Lyubomirsky, S. (2010). Persistent pursuit of needsatisfying goals lead to increased happiness: A 6-months longitudinal experimental study. Motivation and Emotion, 34(1), 39- 48. DOI: 10.1007/s11031-009-9153-1

Siddoway, R. (2013). Grit. The Rosen Publishing Group. 
Singh, K., \& Jha, S.D. (2008). Positive and negative affect, and grit as predictors of happiness and life satisfaction. Journal of the Indian Academy of Applied Psychology, 34, 40-45.

Singh, K., \& Jha, S.D. (2008). Positive and negative affect, and grit as predictors of happiness and life satisfaction. Journal of the Indian Academy of Applied Psychology, 34(2), 40-45.

Singh, k., Junnakar, M., \& Mitra, S. (2018). Validation of Hindi translated scales on Grit, Resilience and Well-being. Journal of the Indian Academic of Applied Psychology, 44(1), 89-98.

Skinner, E.A., Pitzer, J.R. \& Brule, H.A. (2014). The role of emotion in engagement, coping and the development of motivational resilience. International Handbook of Emotions in Education. Publisher Taylor and Francis Group.

Snyder, C.R. (1994). The psychology of hope: You can get there from here. Simon and Schuster. 12.

Snyder, C.R., Irving, L.M., \& Anderson, J.R. (1991). Hope and health. Handbook of social and clinical psychology: The Health Perspective, 162, 285-305.

Snyder, C.R., LaPointe, A.B., Jeffrey Crowson, J., Early, S. (1998). Preferences of high-and low-hope people for self-referential input. Cognition \& Emotion, 12(6), 807-823.

Snyder, C.R., Michael, S.T., \& Cheavens, J.S. (1999). Hope as a psychotherapeutic foundation of nonspecific factors, placebos, and expectancies. In M. A. Huble, B. Duncan, \& S. Miller (Eds.), Heart and soul of change (pp. 179-200). Washington, DC: American Psychological Association.

Snyder, C.R., Michael, S.T., \& Cheavens, J.S. (1999). Hope as a psychotherapeutic foundation of nonspecific factors, placebos, and expectancies. In M. A. Huble, B. Duncan, \& S. Miller (Eds.), Heart and soul of change (pp. 205-230). Washington, DC: American Psychological Association.

Southwick, S.M., \& Charney, D.S. (2012). The Science of Resilience: Implications for the Prevention and treatment of depression. Science, 79-82.

Steger, M. \& Kashdan, T. (2007). Stability and specificity of meaning in life and life satisfaction over one year. Journal of Happiness Studies, 8, 161179.

Steger, M.F., Frazier, P., Oishi, S., \& Kaler, M. (2006). The Meaning in Life Questionnaire: Assessing the presence of and search for meaning in life. Journal of Counseling Psychology, 53, 80-93.

Steger, M., \& Shin, J.Y. (2010). The relevance of the Meaning in Life Questionnaire to therapeutic practice: A look at initial evidence. The International Forum for Logotherapy, 33, 95- 104. 
Steger, M., Frazier, P., Oishi, S. \& Kaler, M. (2006). The meaning in life questionnaire: assessing the presence of and search for meaning in life. Journal of Counseling Psychology, 53(1), 80 - 93.

Stone, A.A., Turkkman, J.S., Bachrach, C.A., Jobe, J.B., Kurtzman, H.S., \& Cain, V.S. (2002). The science of self-report: Implications for research and practice. Mahwah, NJ: Erlbaum

Tang, X., Wang, M-T., Guo, J., \&Salmela-Aro, K. (2019). Building grit: The longitudinal pathways between mindset, commitment, grit, and academic outcomes. Journal of Youth and Adolescence, 48, 850-863. https://doi.org/10.1007/s10964-019-00998-0

Tiittanen, M. (2014). Grit and Different Aspects of Well-being: Direct and Indirect Effects via Sense of Coherence and Authenticity. Master's Thesis Spring. Department of Psychology, Lunds University.

Vainio, M.M., \& Daukantaite, D. (2015). Grit and Different Aspects of Well-Being: Direct and Indirect Relationships via Sense of Coherence and Authenticity. Journal of Happiness Studies, 1-29.

Valois, R.F., Paxton, R.J., Zullig, K.J. \& Huebner, E.S. (2006). Life satisfaction and violent behaviors among middle school students. Journal of Child and Family Studies, 15(6), 695 - 707.

Vela, J.C., Castro, V., Cavazos, L., Cavazos, M., \& Gonzalez, S.L. (2014). Understanding Latina/o students' meaning in life, spirituality, and subjective happiness. Journal of Hispanic Higher Education, 14, 171184. doi:1177/1538192714544524

Vela, J.C., Ikonomopoulos, J., Lenz, A.S., Hinojosa, Y., \& Saldana, K. (2017). Evaluation of the Meaning in Life Questionnaire and Dispositional Hope Scale with Latina/o students. Journal of Humanistic Counseling, 56, 166-179. doi:10.1002/johc.12051

Vela, J.C., Lu, M.-T. P., Lenz, A.S., \& Hinojosa, K. (2015). Positive psychology and familial factors as predictors of Latina/o students' psychological grit. Hispanic Journal of Behavioral Sciences, 37, 287-303.

Vela, J.C., Smith, W.D., Whittenber, J.F., Guardila, R., \& Savage, M. (2018). Positive psychology factors as predictors of Latina/o college students' psychological grit. Journal of Multicultural Counseling \& Development, 46(1), 02-19.

$\mathrm{Wu}$, A.M.S., Lei, L.L., \& Ku, L. (2013). Psychological needs, purpose in life, and problem video game playing among Chinese young adults. Int. J. Psychol, 48, 583-590. 